\title{
The roles of transforming growth factor- $\beta$, Wnt, Notch and hypoxia on liver progenitor cells in primary liver tumours (Review)
}

\author{
ELIENE BOGAERTS $^{1}$, FEMKE HEINDRYCKX ${ }^{2}$, YVES-PAUL VANDEWYNCKEL ${ }^{1}$, \\ LEO A. VAN GRUNSVEN ${ }^{3}$ and HANS VAN VLIERBERGHE ${ }^{1}$
}

${ }^{1}$ Department of Gastroenterology and Hepatology, 1K12, Ghent University Hospital, 9000 Gent, Belgium;
${ }^{2}$ Department of Medical Biochemistry and Microbiology, Uppsala University, 75123 Uppsala, Sweden;
${ }^{3}$ Department of Cell Biology, Liver Cell Biology Lab, Vrije Universiteit Brussel, 1090 Brussels, Belgium

Received October 25, 2013; Accepted November 28, 2013

DOI: $10.3892 /$ ijo.2014.2286

\begin{abstract}
Primary liver tumours have a high incidence and mortality. The most important forms are hepatocellular carcinoma and intrahepatic cholangiocarcinoma, both can occur together in the mixed phenotype hepatocellular-cholangiocarcinoma. Liver progenitor cells (LPCs) are bipotential stem cells activated in case of severe liver damage and are capable of forming both cholangiocytes and hepatocytes. Possibly, alterations in Wnt, transforming growth factor- $\beta$, Notch and hypoxia pathways in these LPCs can cause them to give rise to cancer stem cells, capable of driving tumourigenesis. In this review, we summarize and discuss current knowledge on the role of these pathways in LPC activation and differentiation during hepatocarcinogenesis.
\end{abstract}

\section{Contents}

1. Introduction

2. Liver progenitor cells

Correspondence to: Dr Hans Van Vlierberghe, Department of Gastroenterology and Hepatology, 1K12, Ghent University Hospital, De Pintelaan 185, 9000 Gent, Belgium

E-mail: hans.vanvlierberghe@ugent.be

Abbreviations: HCC, hepatocellular carcinoma; ICC, intrahepatic cholangiocarcinoma; CHC, hepatocellular-cholangiocarcinoma; TACE, transarterial chemoembolisation; HIF, hypoxia inducible factor; CSC, cancer stem cell; LPC, liver progenitor cell; TGF- $\beta$, transforming growth factor- $\beta$; CD133, prominin 1 ; EpCAM, epithelial cell adhesion molecule; AFP, $\alpha$-fetoprotein; CK19, cytokeratin 19; ECM, extracellular matrix; EMT, epithelial mesenchymal transition; OV6, oval cell marker 6; NICD, Notch intracellular domain

Key words: hepatic cancer, liver progenitor cell, cancer stem cells, Wnt receptors, TGF- $\beta$, Notch receptors, hypoxia inducible factor 1
3. Liver progenitor cells in hepatic carcinogenesis

4. Role of hypoxia in hepatic carcinogenesis and progenitor cell activation

5. Conclusion

\section{Introduction}

Liver cancer is one of the most frequently diagnosed cancers worldwide. Despite efforts made, these tumours are often detected in an advanced stage, making liver cancer the third most deadly cancer worldwide (1). The most important types of primary liver cancer are hepatocellular carcinoma (HCC) and intrahepatic cholangiocarcinoma (ICC). HCC often develops in a background of chronic liver disease caused by chronic alcohol abuse, viral hepatitis or non-alcoholic steatohepatitis, while less is known on potential risk factors for ICC. Both primary tumours can be found together in combined hepatocellular-cholangiocarcinoma $(\mathrm{CHC})$, which is characterised by a worse prognosis than $\operatorname{HCC}$ or $\operatorname{ICC}(2,3)$. There are several curative therapeutic options for primary liver tumours including resection, transplantation and radiofrequency ablation. However, more often than not, these tumours are detected in late stages. At this point, existing therapies including antiangiogenic compounds such as sorafenib, and transarterial chemoembolisation (TACE) (4), mainly aim to slow down tumour growth and increase survival. Unfortunately, these treatment strategies still hold various serious adverse effects and therapy resistance, relapse and metastasis remain a real threat (4-6). Importantly, anti-angiogenic treatment also sometimes causes increased local invasion and metastasis, worsening tumour progression (5). Finally, a phenotypic switch from HCC to $\mathrm{CHC}$ has been reported after both TACE and increased hypoxia inducible factor (HIF) stabilisation in a mouse model for HCC $(6,7)$.

Cancer stem cells (CSC) are cancer cells that possess stem cell characteristics such as the ability to differentiate to all cell types found in a particular cancer sample and are associated with relapse and metastasis $(8,9)$. Recently, interest has grown in the existence of liver CSC with a liver progenitor 
cell (LPC) gene signature, LPCs are triggered during severe acute or chronic liver injury, during which proliferation of mature hepatocytes is inhibited (10). LPC-progeny can express hepatocyte- or cholangiocyte-specific lineage markers and experimentally have been proven to differentiate into either of these cell types (11-13).

Possibly, adverse effects often seen following treatment could be caused by survival and adaptation of LPC derived CSC. This would indicate that LPCs could not only play a role in tumour initiation, but also in progression and therapy resistance (14-17).

This review briefly summarizes the current knowledge on signalling pathways acting in primary liver tumour biology, specifically their involvement in LPC activation and proliferation, as well as a possible relation between LPCs and CSCs.

\section{Liver progenitor cells}

In case of severe hepatic damage, such as in elaborate chronic liver injury, when proliferation of hepatocytes and/or cholangiocytes alone is insufficient to restore the liver mass and function, liver progenitor cells (LPCs) are stimulated to proliferate and replace the damaged cell types (12). Even though LPCs can most commonly be found in the canals of Hering $(18,19)$, several other possible locations have been described: intralobular bile ducts, peri-ductal cells and peribiliary hepatocytes (20). Possibly, the LPC niche also consists of other actors in liver damage, such as hepatic stellate cells and Kupffer cells (21-23). Differential interaction with these cells could account for the different observations concerning LPC location and factors involved in their activation in various models of liver injury $(19,22,23)$.

The most commonly used markers for identification of LPCs, or determination of cells with LPC-like characteristics are Prominin 1 (CD133), epithelial cell adhesion molecule (EpCAM), $\alpha$-fetoprotein (AFP), and (cyto-) keratin 19 (CK19). However, many other stem cell, hepatic and cholangiocytic markers are used to characterize LPCs (Table I) (24-26).

Although the existence of LPCs and their role in liver injury is generally accepted, and a broad range of markers is being used to identify and/or isolate these cells from livers (13,19,27-29), researchers have not yet agreed on a precise set of markers defining the LPC population, therefore filtering out the identity of the 'true progenitor cell', remains a challenge.

\section{Liver progenitor cells in hepatic carcinogenesis}

Several studies have shown that cells with LPC characteristics are part of the tumour niche in primary liver tumours (30-32). Because of their multipotent characteristics there probably is a role for LPCs in HCC and ICC formation, however, due to the dual hepatocytic and cholangiocytic origin, it is the $\mathrm{CHC}$ that is generally presumed to be a progenitor derived tumour $(30,33)$.

Currently, there are two major hypotheses on how stem cells influence tumour formation. Firstly, the clonal evolution model, which presumes that a single cell acquires random mutations and gives rise to a group of identical tumour cells, each with equal potential to generate a tumour. Secondly, the cancer stem cell theory proposes that a tumour consists of a heterozygous cell population, where only certain cells are able to self-renew and differentiate (9).

Over the years, CSC have been shown to play a role in the development of certain forms of leukaemia and glioblastoma, as well as in several solid tumours such as breast, gastric and colon cancer $(15,24,34)$ and are now being extensively studied in hepatocarcinogenesis $(15,24)$.

The predisposition of primary liver tumours to develop in a background of chronic liver disease in which there is an increased proliferation of progenitor cells $(2,7)$ increases the likelihood of progenitor cells accumulating and stabilising enough mutations to obtain a cancerous phenotype. It may thus be possible for LPCs to transform into (hepatic) cancer stem cells and grow into primary liver tumours $(15,24)$.

So far, several pathways have been shown to mediate LPC activation, proliferation and/or differentiation. The balance between Wnt and Notch signalling has been proposed to be crucial for determination of the LPC cell fate. Activation of the Notch pathway is essential for biliary differentiation, as shown by several in vivo and in vitro experiments $(35,36)$. Moreover, in case of hepatocyte injury, activation of the canonical Wnt pathway, probably prevents activation of the Notch pathway, thus pushing LPC differentiation towards hepatocytes $(35,36)$. Also, interaction between tumour cells and the extracellular matrix (ECM) is shown to be essential for tumour progression, invasion and metastasis, transforming growth factor $\beta$ (TGF- $\beta$ )-mediated epithelial mesenchymal transition (EMT) plays an important role in this interaction (37). Recently TGF- $\beta$ signalling has also been linked to the presence of LPCs in hepatocarcinogenesis (38).

The Notch, Wnt and TGF- $\beta$ pathways are also well known to be involved in many tumourigenic processes. In this review we will focus on these three pathways and discuss their role in hepatocarcinogenesis, with special attention to their potential involvement in LPC and/or CSC-mediated tumour initiation and progression (Fig. 1).

Wnt/ $\beta$-catenin pathway. The canonical Wnt signalling pathway directs essential cell regulatory mechanisms such as cell proliferation and cell polarity, but also plays an important role during embryonic development (39-41).

A key player in the canonical Wnt signalling pathway is $\beta$-catenin, which also plays a crucial role in intracellular junctions by forming a receptor complex with epithelial cadherin (E-cadherin) (39). Upon binding of Wnt to its receptor Frizzled, $\beta$-catenin switches from being part of a destruction complex to the formation of a 'Wnt-signalosome' that prevents $\beta$-catenin degradation. This allows the latter to migrate to the nucleus where it binds to the T-cell factor/lymphoid enhancer factor and induces transcriptional activation of Wnt-responsive genes $(39,42)$. This $\beta$-catenin signalling has been shown to be necessary for mouse LPC activation upon injury in rodents (43) and to regulate the hepatocytic specification of LPCs (35).

In HCC cell lines, activation of the Wnt/ $\beta$-catenin signalling pathway not only increases EpCAM accumulation in both the cytoplasm and the nucleus (42), but also increases the $\mathrm{EpCAM}^{+} \mathrm{AFP}^{+}$and the oval cell marker $6(\mathrm{OV} 6)^{+}$population. These represent cell populations with strong LPC features 
Table I. Selection of LPC markers and their potential role in hepatocarcinogenesis.

\begin{tabular}{|c|c|c|}
\hline Abbreviation & Full name & Role in HCC and/or CC development \\
\hline CK7 & (cyto) keratin 7 & Increased expression of these cholangiocytic markers in primary liver \\
\hline CK19 & (cyto) keratin 19 & tumours indicate poor prognosis $(16,87)$ \\
\hline ALB & Albumin & $\begin{array}{l}\text { Hepatocyte-specific marker, upregulated in ICC, compared to other } \\
\text { cholangiocellular tumours like extrahepatic cholangiocarcinoma }(88,89)\end{array}$ \\
\hline OPN & Osteopontin & $\begin{array}{l}\text { Restricted to cholangiocytes lining the canals of Hering, good LPC marker } \\
\text { for lineage studies (12) }\end{array}$ \\
\hline OCT4/Pou5f1 & $\begin{array}{l}\text { Octamere binding transcription } \\
\text { factor/Pou domain class } 5 \\
\text { transcription factor } 1\end{array}$ & $\begin{array}{l}\text { Embryonic transcription factor involved in stem cell self-renewal. Possible } \\
\text { prognostic marker for HCC, and upregulated in chemoresistant liver cancer } \\
\text { cells }(90)\end{array}$ \\
\hline AFP & $\alpha$-fetoprotein & $\begin{array}{l}\text { Fetal serum protein, often but not always re-expressed in HCC and CHC } \\
(89,91)\end{array}$ \\
\hline LIF & Leukemia inhibitory factor & $\begin{array}{l}\text { Cells are pushed to differentiate during decreased LIF levels. LIF is elevated } \\
\text { in LPCs and known to induce acute phase proteins in hepatocytes (92). }\end{array}$ \\
\hline Sox 9 & $\begin{array}{l}\text { SRY-related HMG box } \\
\text { transcription factor } 9\end{array}$ & Transcription factor involved in cholangiocyte-specific development (93) \\
\hline CD133 & Prominin 1 & $\begin{array}{l}\text { Cancer stem cell marker, upregulated in most primary liver cancers. } \\
\text { Associated with more aggressive phenotype and therapy resistance (94-96) }\end{array}$ \\
\hline CD34 & CD34 antigen & Cancer cell marker mainly expressed in early hematopoietic cells. \\
\hline CD44 & CD44 antigen & $\begin{array}{l}\text { Upregulated in most primary liver cancers, regulation associated with more } \\
\text { aggressive phenotype and treatment resistance (96) }\end{array}$ \\
\hline CD56/NCAM & Neural cell adhesion molecule & $\begin{array}{l}\text { Shift from E-cadherin to NCAM expression indicates epithelial- } \\
\text { mesenchymal transition }\end{array}$ \\
\hline CD117 & c-Kit & $\begin{array}{l}\text { Proto-oncogene, upregulation due to mutation occurs in many tumours. } \\
\text { C-Kit inhibition is also reported to slow LPC expansion and tumour } \\
\text { formation in rodents (97) }\end{array}$ \\
\hline
\end{tabular}

which also demonstrate tumourigenic and invasive capacities $(41,44)$. Canonical signalling probably also plays a role in chemoresistance, which is strongly linked to LPC proliferation $(45,46)$, as shown by the increased EpCAM expression in patients with reduced sensitivity to interferon $\alpha / 5$-fluorouracil combination therapy (46). In addition, blocking the Wnt/ $\beta$ catenin pathway not only inhibits HCC cell growth (42), but also diminishes chemoresistant $\mathrm{OV}^{+}$colonies (41).

Interestingly, canonical and non-canonical Wnt pathways seem to have opposing effects on tumour growth (47-49). The canonical pathway (mediated by Wnt1-3) mediates growth and regeneration and is reported activated in well differentiated HCC cells while it is repressed in poorly differentiated HCC cell lines $(41,43,49)$. Oppositely, activating the non-canonical pathway (including Wnt5a and 11) has been shown to inhibit HCC and ICC growth (47-49), possibly by antagonizing the canonical pathway, and promoting cell motility and invasion (49). This could indicate an important role in the growth and migration pattern of the tumour, caused by interaction between these two pathways during hepatocarcinogenesis.
Transforming growth factor- $\beta$ pathway. TGF- $\beta$ is involved in various cellular functions, such as cell growth, differentiation and apoptosis, both in adult as well as in embryonic stages (50). Binding of TGF- $\beta$ to its receptor results in phosphorylation of the receptor eventually followed by the translocation of Smad proteins $(\mathrm{Smad} 2 / 3)$ to the nucleus in a complex with Smad4 (coSmad), where they can regulate transcription by binding to Smad-binding elements in co-operation with a plethora of Smad interacting proteins $(51,52)$. However, TGF- $\beta$ also uses non-Smad signaling pathways such as the phosphoinositide 3-kinase/Akt/mTOR pathway, the p38 and Jun N-terminal kinase/mitogen-activated protein kinase pathway to transduce its signals (53). In addition to these non-canonical pathways, TGF- $\beta$ signalling is regulated at many levels by processes such as endocytosis of the receptor complex, or by molecules like inhibitory Smads6/7 and the bio-activity of the ligands through proteolytic cleavage by their protease (mainly furin) (51).

Like its regulation, the role of TGF- $\beta$ in tumour formation is rather complicated. In healthy tissue, it acts as a tumour 


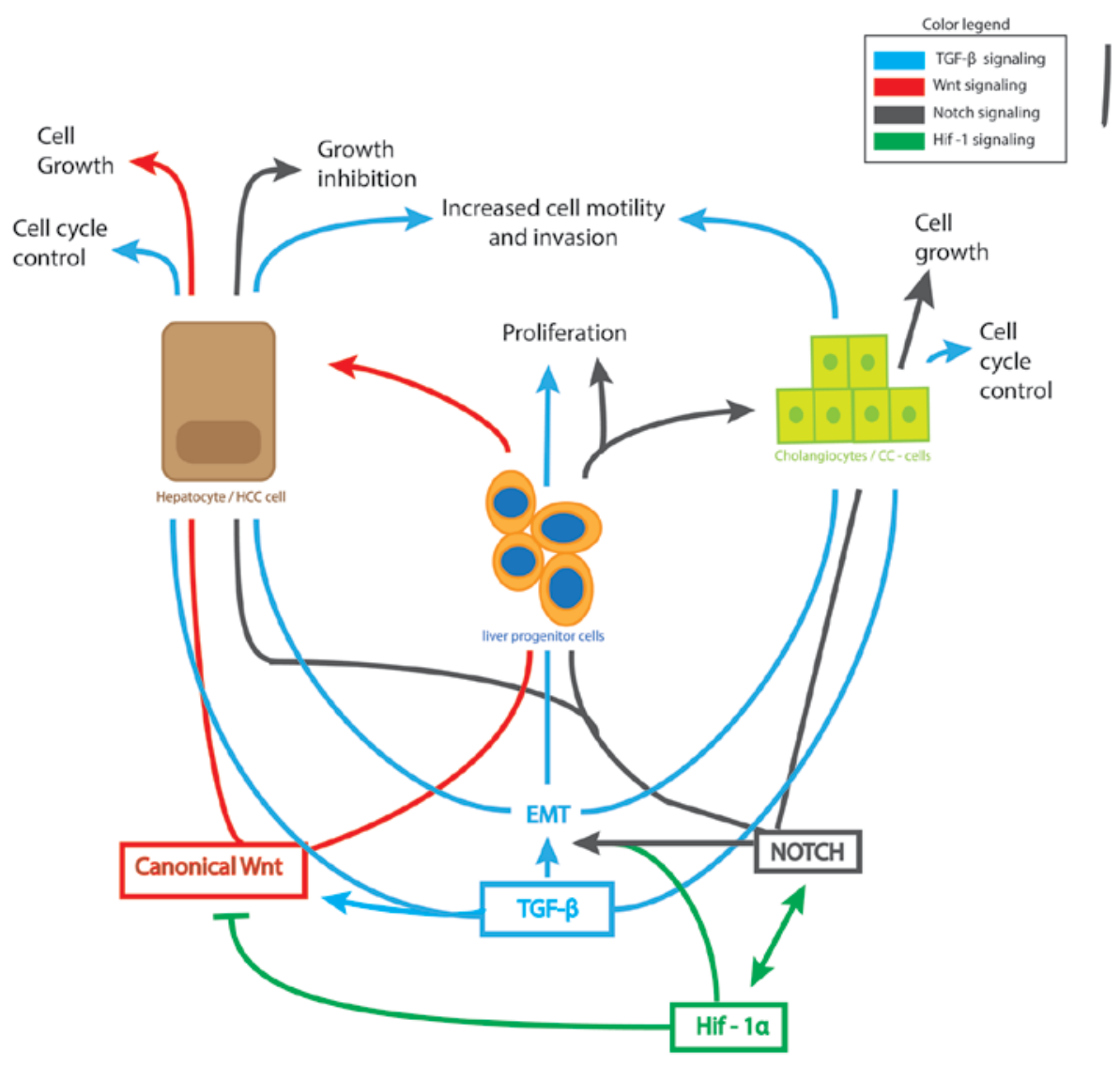

Figure 1. Schematic representation of the role of Wnt, Notch, TGF- $\beta$ and Hif-1 $\alpha$ signalling in hepatocytes, cholangiocytes and liver progenitor cells in hepatocarcinogenesis. The cell growth promoting effects of the Wnt and Notch pathways on hepatocytes and cholangiocytes, respectively, as well as their differential role on liver progenitor cells. The complicated dual role of TGF- $\beta$ as guardian of cell cycle control, as well as its tumour promoting and invasion and metastasis inducing potential in all cell types is visualised. Finally, the complex interactions between these three pathways, and the possible influence of the HIF-1 pathway is presented.

suppressor controlling the cell cycle, inducing apoptosis and regulating autophagy. During tumourigenesis, cells switch their response to TGF- $\beta$, making it a potent inducer of cell motility, invasion and metastasis, as well as guardian of stem cell maintenance (54). In liver carcinogenesis, TGF- $\beta$ has been shown to have both tumour suppressing and promoting effects $(24,50)$ and its expression is decreased in early, while increased in later stages of tumourigenesis $(24,55,56)$.

TGF- $\beta$ signalling is also a master regulator of initiating and maintaining EMT, the process directing cancer cells towards invasion and metastasis (37). In HCC cells, inhibition of TGF- $\beta$ has been reported to upregulate epithelial-cadherin (E-cadherin) and thereby lower migration and invasion potential (57). However, in human fetal hepatocytes (cells carrying progenitor cell features, like EpCAM and CK19 as well as hepatoblast features like AFP), TGF- $\beta$ even induces apoptotic, growth inhibitory signals, as well as pro-invasive, mesenchymal characteristics such as neuronal cadherin, Snail and vimentin (57). What is more, during EMT, TGF- $\beta$ signalling results in dissociation of $\beta$-catenin from the E-cadherin/ $\beta$-catenin membrane complex resulting in cytoplasmatic and nuclear accumulation of $\beta$-catenin and subsequent activation of the Wnt pathway (58). Possibly, this upregulation of the Wnt pathway, due to TGF- $\beta$ dysregulation causes a larger population of activated LPCs in HCC patients (59) and in mice following partial hepatectomy (60). Furthermore, in patients, high nuclear $\beta$-catenin accumulation is correlated with higher vascular invasion grades and increased recurrence after transplantation (59).

These data suggest an important, but contradictory role for TGF- $\beta$ signalling in hepatocarcinogenesis, possibly regulating the activation and differentiation of LPCs, through regulation of the Wnt-signalling pathway. Because of the important role of TGF- $\beta$ in EMT, its regulation is decisive for the invasive and metastatic potential of the tumours.

Notch pathway. The Notch pathway is important in stem cell self-renewal, differentiation, and plays a special role in the control of many binary cell fate choices in embryonic and adult cells (61). In the liver, Notch signalling promotes differentiation of LPCs towards the cholangiocytic lineage rather than to hepatocytes (62). Furthermore, Notch is involved in several fundamental cell regulatory processes such as proliferation, apoptosis and EMT (61). Binding of Delta or Jagged ligand to the Notch receptor, causes cleavage of the extracellular C-terminal peptide. Notch intracellular domain (NICD) is then cleaved by $\gamma$-secretase, releasing it into the cytoplasm so it can migrate to the nucleus, bind to CSL, recruit co-activators such as mastermind-like, and induce Notch-dependent gene transcription. The two major targets are the Hairy and 
Hes-related repressor protein families of transcription factors $(61,63)$

Like the Wnt and TGF- $\beta$ pathway, aberrant Notch signalling is well described in many different kinds of cancer, such as breast, lung, colorectal, pancreatic and hepatic cancer $(24,63)$. However, deregulation of the Notch pathway has been described as both oncogenic and tumour suppressive, depending on tissue type and circumstances (63-65).

For example, the effect of Notch signalling on hepatocarcinogenesis can be determined by its effect on several players in cell cycle control such as p53 (65), cyclin-A, -D1 and -E (64). Induction of p53 in HepG 2 cells, leads to an increased expression of NICD and downregulation of the cells proliferative capacity, but not the other way around. Moreover, in cells expressing mutant p53, not able to induce NICD upregulation, administration of recombinant NICD protein did cause reduced proliferation (65).

In a different HCC cell line, SMMC7721, NICD overexpression by retroviral transfection did cause increased p53 levels, as well as decreased levels of proteins involved in cell cycle control, like phosphorylated forms of the retinoblastoma protein, thus also causing inhibition of growth and proliferation (64). Unfortunately neither of these studies investigated the LPC properties of the used cells, before nor after p53 or NICD induction.

In accordance, Notch pathway inhibition by DAPT ( $\gamma$-secretase inhibitor) in adult mice after conditional deletion of retinoblastoma protein family genes in the liver, which causes proliferation of the progenitor compartment, resulted in an increased number of HCC nodules (66). Also, over-activation of NICD inhibits cell proliferation in tumour cell lines derived from these retinoblastoma-deficient mice, but not in HepG2 cells (66). These data suggest a differential role for the Notch pathway in progenitor cells compared to hepatocytes, further supported by recent findings of hepatocyte-specific NICD overexpression causing development of HCC with $100 \%$ penetrance after 12 months (67) and ICC after partial hepatectomy (68).

Finally, Notch signalling has also been related to therapy resistance; Delta-like ligand induced activation of the Notch pathway seems to mediate tumour resistance to anti-angiogenic therapy by activating escape mechanisms in the tumour causing the formation of new vessels circumnavigating the therapy-induced blockage $(69,70)$.

\section{Role of hypoxia in hepatic carcinogenesis and progenitor cell activation}

In the presence of oxygen, HIF is quickly hydroxylated by prolyl hydroxylase domain proteins, causing degradation. However, in hypoxic conditions, shortage of hydroxyl-groups leads to HIF stabilisation and migration to the nucleus where it regulates processes supporting cell survival under hypoxic conditions, for example by increasing (neo)angiogenesis (71). Primary liver tumours, especially HCC, often develop in a background of chronic liver disease, characterised by fibrogenesis, eventually leading to cirrhosis. This process is accompanied by increased hypoxia, caused by sinusoidal capillarisation and formation of fibrotic septa increasing resistance to blood flow and thus decreasing oxygen delivery to liver cells. In addition, the fast growing liver tumours quickly outgrow the existing liver vascularisation, thus creating hypoxic conditions $(7,72,73)$.

Current treatment strategies for advanced stage liver cancer, such as anti-angiogenic treatment or TACE, often aim to deprive the tumour of its blood and nutrient supply (4). However, therapy resistance to TACE and anti-angiogenic treatment has been attributed to induction of hypoxic conditions and activation of HIF $(3,7,74)$, by adversely increasing cancer cell survival and tumour growth.

Recently, a significant increase in stem cell marker expression has been seen in vitro after exposure of HCC cultures to hypoxia (75). Possibly, the decreased oxygen levels in tumour cells stimulate dedifferentiation towards a progenitor phenotype. Potentially increased proliferation and altered differentiation of LPCs in HCC also cause the phenotypic switch to $\mathrm{CHC}$ in prolyl hydroxylase domain 2 heterozygous mice, which are characterised by increased HIF stabilisation $(3,7)$ and in patients, after receiving TACE treatment (6).

These findings have raised many questions about the future of these therapies, since monotherapies are often insufficient in treatment of HCC and can even induce more aggressive disease. It is of vast importance to consider alternative therapeutic strategies that prevent this massive hypoxic response. For example, a recent study has shown a better outcome in mice with HCC, after treatment with anti-placental growth factor, causing vascular normalisation, instead of blocking neoangiogenesis, and thus causing less hypoxia (3). Also, administration of EF24, could synergistically enhance the antitumour effects of sorafenib, reduce metastasis and overcome sorafenib resistance through inhibiting HIF-1 $\alpha$ by sequestering it in the cytoplasm and promoting degradation by upregulating the Von Hippel-Lindau tumour suppressor in five different cell lines and in both xenograft and orthotopic mouse models for HCC (76).

Possibly, a HIF-dependent alterations to the Wnt, Notch and/or TGF- $\beta$ pathways are responsible for the observed reaction of tumour tissue to hypoxia inducing therapies. Both in vitro and in vivo experiments have shown crosstalk between the Wnt and HIF pathways, depletion of $\beta$-catenin resulted in more severe hepatic injury in a mouse model for liver perfusion while an increased Wnt signalisation resulted in a marked decrease of hepatic injury compared to control (77). In this study, Wnt1 overexpression resulted in a significant higher response of HIF sensitive genes and HIF1 $\alpha$ protein levels, While $\beta$-catenin/T-cell factor target gene expression was significantly reduced after ischemia, without a decrease in total $\beta$-catenin. The observation was further supported in HCC cells in vitro, where a direct interaction between HIF1 $\alpha$ and $\beta$-catenin was shown, enhancing HIF1 $\alpha$ signaling and driving EMT (78). Thus, in hypoxic conditions, HIF1 $\alpha$ competes with the lymphoid enhancer factor for binding of transcriptional activator $\beta$-catenin inhibiting the canonical Wnt pathway responsible for hepatocyte proliferation and instead promoting adaptation, survival and EMT through HIF signalling $(77,78)$. This further demonstrates the potency for intratumoural hypoxia to push LPC differentiation towards a more aggressive, therapy-resistant cancerous offspring.

Furthermore, the epithelial mesenchymal transition of hepatocytes could also contribute to dedifferentiation of 
hepatocytes towards a stem/progenitor-like phenotype as seen in vitro (79). EMT in hypoxic conditions is probably accomplished by HIF mediated activation of the TGF- $\beta$ pathway $(80,81)$. Next to the $\beta$-catenin induced intensification, Notch1 signaling has been shown not only essential for HIF and snail mediated EMT $(82,83)$, but also capable of inducing EMT in normoxic conditions by directly targeting Snail in breast cancer cell lines (83). However, in an HCC cell line a direct interaction between NICD and Snail in the cytoplasm has been shown to result in ubiquitinylation and degradation of Snail (84), again, showing the complex nature of these cell-type specific interactions.

\section{Conclusion}

Despite the increase in scientific interest, the role of LPCs in cancer progression is still unclear. These bipotential progenitor cells could shift to a cancerous phenotype and give rise to $\mathrm{HCC}$, ICC and $\mathrm{CHC}$, and not only regulating tumour initiation and growth, but also the invasive and metastatic potential. Likely, specific interactions between several pathways involved in regulation of LPCs can be modulated by intrinsic as well as extrinsic factors and is capable of driving tumourigenesis and determining its phenotype. Of the 3 main liver tumours potentially derived from LPCs, CHC is most suitable to study the role of bipotential cells during tumour formation, since it consists of both hepatocyte- and cholangiocyte-like cells (85). We discussed a role for altered regulation of Notch, Wnt, HIF and TGF- $\beta$ signalling in primary liver tumour development. Interactions between these pathways could possibly force a group of progenitor or cancer stem cells to behave differently, causing a tumour to exhibit both HCC and ICC-like characteristics.

There is also a potential role for hypoxia in the determination of cell fate in LPCs, possibly not only by triggering conversion of its tumourigenic offspring to a more malignant, mixed phenotype $(6,7)$, but also by inducing therapy resistance $(69,86)$. As discussed here, the major target of altered signalling could be the EMT, a major process in malignant conversion, provoking hepatocytes to exhibit more stem/progenitor-like features and thus increasing the pool of cancer cells with an LPC signature.

These findings are of particular interest when using therapies altering the signalling of one or more of these pathways, triggering changes which could potentially lead to more aggressive tumours. More specifically, inhibiting the involvement of the Notch, Wnt or TGF- $\beta$ pathway could be the key to altering the massive response to hypoxia and would allow us to reduce the adverse effects so often caused by hypoxia-inducing therapy.

\section{Acknowledgements}

Eliene Bogaerts received funding through an 'Emmanuel van der Schueren' research grant by the Flemish league against cancer (VLK). Femke Heindryckx received funding from the Wenner-Gren Foundation - Sweden. Yves-Paul Vandewynckel received a scholarship from the University Ghent Research Fund (BOF). Leo A. van Grunsven is a Research Professor at the Vrije Universiteit Brussel and LPC-related work in his lab is funded by the Fonds Wetenschappelijk Onderzoek
(FWO-G033313N) in Flanders and an Belgium interuniversity attraction poles project P7-47 entitled 'HEPRO II' (Belspo). Hans Van Vlierberghe is a senior clinical investigator of the Research Foundation - Flanders (FWO).

\section{References}

1. Jemal A, Bray F, Center MM, Ferlay J, Ward E and Forman D: Global Cancer Statistics. CA Cancer J Clin 61: 69-90, 2011.

2. Braillon A: Hepatocellular carcinoma. Lancet 380: 469, 2012.

3. Heindryckx F, Bogaerts E, Coulon SH, Devlies H, Geerts AM, Libbrecht L, Stassen JM, et al: Inhibition of the placental growth factor decreases burden of cholangiocarcinoma and hepatocellular carcinoma in a transgenic mouse model. Eur J Gastroenterol Hepatol 24: 1020-1032, 2012.

4. de Lope CR, Tremosini S, Forner A, Reig M and Bruix J: Management of HCC. J Hepatol 56: S75-S87, 2012.

5. Paez-Ribes M, Allen E, Hudock J, Takeda T, Okuyama H, Vinals $\mathrm{F}$, Inoue $\mathrm{M}$, et al: Antiangiogenic therapy elicits malignant progression of tumors to increased local invasion and distant metastasis. Cancer Cell 15: 220-231, 2009.

6. Zen C, Zen Y, Mitry RR, Corbeil D, Karbanova J, O'Grady J, Karani J, et al: Mixed phenotype hepatocellular carcinoma after transarterial chemoembolization and liver transplantation. Liver Transplant 17: 943-954, 2011.

7. Heindryckx F, Kuchnio A, Casteleyn C, Coulon S, Olievier K, Colle I, Geerts A, et al: Effect of prolyl hydroxylase domain-2 haplodeficiency on the hepatocarcinogenesis in mice. J Hepatol 57: 61-68, 2012.

8. Tong CM, Ma S and Guan XY: Biology of hepatic cancer stem cells. J Gastroenterol Hepatol 26: 1229-1237, 2011

9. Reya T, Morrison SJ, Clarke MF and Weissman IL: Stem cells, cancer, and cancer stem cells. Nature 414: 105-111, 2001.

10. Forbes S, Vig P, Poulsom R, Thomas H and Alison M: Hepatic stem cells. J Pathol 197: 510-518, 2002.

11. Yovchev MI, Grozdanov PN, Zhou H, Racherla H, Guha C and Dabeva MD: Identification of adult hepatic progenitor cells capable of repopulating injured rat liver. Hepatology 47: 636-647, 2008.

12. Espanol-Suner R, Carpentier R, Van Hul N, Legry V, Achouri Y, Cordi S, Jacquemin P, et al: Liver progenitor cells yield functional hepatocytes in response to chronic liver injury in mice. Gastroenterology 143: 1564-1575, 2012.

13. Shin S, Walton G, Aoki R, Brondell K, Schug J, Fox A, Smirnova O, et al: Foxll-Cre-marked adult hepatic progenitors have clonogenic and bilineage differentiation potential. Genes Dev 25: 1185-1192, 2011.

14. Roskams T: Liver stem cells and their implication in hepatocellular and cholangiocarcinoma. Oncogene 25: 3818-3822, 2006.

15. Ma S, Chan KW, Hu L, Lee TKW, Wo JYH, Ng IL, Zheng BJ, et al: Identification and characterization of tumorigenic liver cancer stem/progenitor cells. Gastroenterology 132: 2542-2556, 2007.

16. Uenishi T, Kubo S, Yamamoto T, Shuto T, Ogawa M, Tanaka H, Tanaka S, et al: Cytokeratin 19 expression in hepatocellular carcinoma predicts early postoperative recurrence. Cancer Sci 94: 851-857, 2003.

17. Lee JS, Heo J, Libbrecht L, Chu IS, Kaposi-Novak P, Calvisi DF, Mikaelyan A, et al: A novel prognostic subtype of human hepatocellular carcinoma derived from hepatic progenitor cells. Nat Med 12: 410-416, 2006.

18. Theise ND, Saxena R, Portmann BC, Thung SN, Yee H, Chiriboga L, Kumar A, et al: The canals of Hering and hepatic stem cells in humans. Hepatology 30: 1425-1433, 1999.

19. Dolle L, Best J, Mei J, Al Battah F, Reynaert H, van Grunsven LA and Geerts A: The quest for liver progenitor cells: a practical point of view. J Hepatol 52: 117-129, 2010.

20. Kuwahara R, Kofman AV, Landis CS, Swenson ES, Barendswaard E and Theise ND: The hepatic stem cell niche: identification by label-retaining cell assay. Hepatology 47: 1994-2002, 2008.

21. Zhang W, Chen XP, Zhang WG, Zhang F, Xiang SA, Dong HH and Zhang L: Hepatic non-parenchymal cells and extracellular matrix participate in oval cell-mediated liver regeneration. World J Gastroenterol 15: 552-560, 2009.

22. Van Hul N, Lanthier N, Suner RE, Quinones JA, van Rooijen N and Leclercq I: Kupffer cells influence parenchymal invasion and phenotypic orientation, but not the proliferation, of liver progenitor cells in a murine model of liver injury. Am J Pathol 179: 1839-1850, 2011. 
23. Pintilie DG, Shupe TD, Oh SH, Salganik SV, Darwiche H and Petersen BE: Hepatic stellate cells' involvement in progenitormediated liver regeneration. Lab Invest 90: 1199-1208, 2010.

24. Mishra L, Banker T, Murray J, Byers S, Thenappan A, He AR, Shetty K, et al: Liver stem cells and hepatocellular carcinoma. Hepatology 49: 318-329, 2009.

25. Villanueva A, Newell P, Chiang DY, Friedman SL and Llovet JM: Genomics and signaling pathways in hepatocellular carcinoma. Semin Liver Dis 27: 55-76, 2007.

26. Chiba T, Kamiya A, Yokosuka O and Iwama A: Cancer stem cells in hepatocellular carcinoma: recent progress and perspective. Cancer Lett 286: 145-153, 2009.

27. Dorrell C, Erker L, Schug J, Kopp JL, Canaday PS, Fox AJ, Smirnova O, et al: Prospective isolation of a bipotential clonogenic liver progenitor cell in adult mice. Genes Dev 25: 1193-1203, 2011

28. Dolle L, Best J, Empsen C, Mei J, Van Rossen E, Roelandt P, Snykers S, et al: Successful isolation of liver progenitor cells by aldehyde dehydrogenase activity in naive mice. Hepatology 55 : 540-552, 2012

29. Huch M, Dorrell C, Boj SF, van Es JH, Li VSW, van de Wetering M, Sato T, et al: In vitro expansion of single Lgr5(+) liver stem cells induced by Wnt-driven regeneration. Nature 494 247-250, 2013

30. Coulouarn C, Cavard C, Rubbia-Brandt L, Audebourg A Dumont F, Jacques S, Just PA, et al: Combined hepatocellularcholangiocarcinomas exhibit progenitor features and activation of Wnt and TGF signaling pathways. Carcinogenesis 33: 1791-1796, 2012.

31. Shimada M, Sugimoto K, Iwahashi S, Utsunomiya T, Morine Y, Imura S and Ikemoto T: CD133 expression is a potential prognostic indicator in intrahepatic cholangiocarcinoma. J Gastroenterol 45: 896-902, 2010

32. Yin SY, Li JJ, Hu C, Chen XH, Yao M, Yan MX, Jiang GP, et al: CD133 positive hepatocellular carcinoma cells possess high capacity for tumorigenicity. Int J Cancer 120: 1444-1450, 2007.

33. Yin X, Zhang BH, Qiu SJ, Ren ZG, Zhou J, Chen XH, Zhou Y, et al: Combined hepatocellular carcinoma and cholangiocarcinoma: clinical features, treatment modalities, and prognosis. Ann Surg Oncol 19: 2869-2876, 2012.

34. Gottschling S, Schnabel PA, Herth FJF and Herpel E: Are we missing the target? Cancer stem cells and drug resistance in non-small cell lung cancer. Cancer Genomics Proteomics 9: 275-286, 2012

35. Boulter L, Govaere O, Bird TG, Radulescu S, Ramachandran P, Pellicoro A, Ridgway RA, et al: Macrophage-derived Wnt opposes Notch signaling to specify hepatic progenitor cell fate in chronic liver disease. Nat Med 18: 572-579, 2012.

36. Spee B, Carpino G, Schotanus BA, Katoonizadeh A, Vander Borght S, Gaudio E and Roskams T: Characterisation of the liver progenitor cell niche in liver diseases: potential involvement of Wnt and Notch signalling. Gut 59: 247-257, 2010

37. Wendt MK, Tian MZ and Schiemann WP: Deconstructing the mechanisms and consequences of TGF-beta-induced EMT during cancer progression. Cell Tissue Res 347: 85-101, 2012

38. Seok JY, Na DC, Woo HG, Roncalli M, Kwon SM, Yoo JE, Ahn EY, et al: A fibrous stromal component in hepatocellular carcinoma reveals a cholangiocarcinoma-like gene expression trait and epithelial-mesenchymal transition. Hepatology 55: 1776-1786, 2012

39. MacDonald BT, Tamai $\mathrm{K}$ and $\mathrm{He} \mathrm{X}$ : Wnt/beta-catenin signaling: components, mechanisms, and diseases. Dev Cell 17: 9-26, 2009.

40. Polakis P: Wnt signaling and cancer. Genes Dev 14: 1837-1851, 2000.

41. Yang W, Yan HX, Chen L, Liu Q, He YQ, Yu LX, Zhang SH et al: Wnt/beta-catenin signaling contributes to activation of normal and tumorigenic liver progenitor cells. Cancer Res 68 : 4287-4295, 2008.

42. Yamashita T, Budhu A, Forgues M and Wang XW: Activation of hepatic stem cell marker EpCAM by Wnt-beta-catenin signaling in hepatocellular carcinoma. Cancer Res 67: 10831-10839,2007.

43. Apte U, Thompson MD, Cui SS, Liu B, Cieply B and Monga SPS: Wnt/beta-catenin signaling mediates oval cell response in rodents. Hepatology 47: 288-295, 2008.

44. Yamashita T, Ji J, Budhu A, Forgues M, Yang W, Wang HY, Jia $\mathrm{H}$, et al: EpCAM-positive hepatocellular carcinoma cells are tumor-initiating cells with stem/progenitor cell features. Gastroenterology 136: 1012-1024, 2009.

45. Abdullah LN and Chow EK: Mechanisms of chemoresistance in cancer stem cells. Clin Transl Med 2: 3, 2013.
46. Noda T, Nagano H, Takemasa I, Yoshioka S, Murakami M, Wada H, Kobayashi S, et al: Activation of Wnt/beta-catenin signalling pathway induces chemoresistance to interferonalpha/5-fluorouracil combination therapy for hepatocellular carcinoma. Br J Cancer 100: 1647-1658, 2009.

47. DeMorrow S, Francis H, Gaudio E, Venter J, Franchitto A, Kopriva S, Onori P, et al: The endocannabinoid anandamide inhibits cholangiocarcinoma growth via activation of the noncanonical Wnt signaling pathway. Am J Physiol Gastrointest Liver Physiol 295: G1150-G1158, 2008.

48. Toyama T, Lee HC, Koga H, Wands JR and Kim M: Noncanonical Wnt11 inhibits hepatocellular carcinoma cell proliferation and migration. Mol Cancer Res 8: 254-265, 2010.

49. Yuzugullu H, Benhaj K, Ozturk N, Senturk S, Celik E, Toylu A, Tasdemir N, et al: Canonical Wnt signaling is antagonized by noncanonical Wnt5a in hepatocellular carcinoma cells. Mol Cancer 8: 90, 2009.

50. Mishra L, Jogunoori W, Johnson L, Tang Y, Katuri V, Shetty K and Mishra B: TGF-beta-signaling is required for ductal progenitor cell survival and epithelial cell differentiation in normal liver. Gastroenterology 128: A353-A353, 2005.

51. Conidi A, Cazzola S, Beets K, Coddens K, Collart C, Cornelis F, Cox L, et al: Few Smad proteins and many Smad-interacting proteins yield multiple functions and action modes in TGF $\beta /$ BMP signaling in vivo. Cytokine Growth Factor Rev 22: 287-300, 2011.

52. van Grunsven LA, Verstappen G, Huylebroeck D and Verschueren K: Smads and chromatin modulation. Cytokine Growth Factor Rev 16: 495-512, 2005

53. Mu Y, Gudey SK and Landström M: Non-Smad signaling pathways. Cell Tissue Res 347: 11-20, 2011.

54. Drabsch Y and ten Dijke P: TGF-beta signalling and its role in cancer progression and metastasis. Cancer Metastasis Rev 31: 553-568, 2012

55. Fausto N: Liver regeneration and repair: hepatocytes, progenitor cells, and stem cells. Hepatology 39: 1477-1487, 2004.

56. Ikegami $\mathrm{T}$ : Transforming growth factor-beta signaling and liver cancer stem cell. Hepatol Res 39: 847-849, 2009.

57. Caja L, Bertran E, Campbell J, Fausto N and Fabregat I: The transforming growth factor-beta (TGF- $\beta$ ) mediates acquisition of a mesenchymal stem cell-like phenotype in human liver cells. J Cell Physiol 226: 1214-1223, 2011.

58. Thiery JP and Sleeman JP: Complex networks orchestrate epithelial-mesenchymal transitions. Nat Rev Mol Cell Biol 7: 131-142, 2006.

59. Zulehner G, Mikula M, Schneller D, van Zijl F, Huber H, Sieghart W, Grasl-Kraupp B, et al: Nuclear beta-catenin induces an early liver progenitor phenotype in hepatocellular carcinoma and promotes tumor recurrence. Am J Pathol 176: 472-481, 2010.

60. Thenappan A, Li Y, Kitisin K, Rashid A, Shetty K, Johnson L and Mishra L: Role of transforming growth factor beta signaling and expansion of progenitor cells in regenerating liver. Hepatology 51: 1373-1382, 2010

61. Fortini ME: Notch signaling: the core pathway and its posttranslational regulation. Dev Cell 16: 633-647, 2009.

62. Zong YW, Panikkar A, Xu J, Antoniou A, Raynaud P, Lemaigre F and Stanger BZ: Notch signaling controls liver development by regulating biliary differentiation. Development 136: 1727-1739, 2009.

63. Yin L, Velazquez OC and Liu ZJ: Notch signaling: emerging molecular targets for cancer therapy. Biochem Pharmacol 80: 690-701, 2010.

64. Qi RZ, An HZ, Yu YZ, Zhang MH, Liu SX, Xu HM, Guo ZH, et al: Notch1 signaling inhibits growth of human hepatocellular carcinoma through induction of cell cycle arrest and apoptosis. Cancer Res 63: 8323-8329, 2003.

65. Lim SO, Park YM, Kim HS, Quan X, Yoo JE, Park YN, Choi GH, et al: Notch1 differentially regulates oncogenesis by wildtype p53 overexpression and p53 mutation in grade III hepatocellular carcinoma. Hepatology 53: 1352-1362, 2011.

66. Viatour P, Ehmer U, Saddic LA, Dorrell C, Andersen JB, Lin CW, Zmoos AF, et al: Notch signaling inhibits hepatocellular carcinoma following inactivation of the RB pathway. J Exp Med 208: 1963-1976, 2011.

67. Villanueva A, Alsinet C, Yanger K, Hoshida Y, Zong YW, Toffanin S, Rodriguez-Carunchio L, et al: Notch signaling is activated in human hepatocellular carcinoma and induces tumor formation in mice. Gastroenterology 143: 1660-1669, 2012. 
68. Zender S, Nickeleit I, Wuestefeld T, Sorensen I, Dauch D, Bozko P, El-Khatib M, et al: A critical role for notch signaling in the formation of cholangiocellular carcinomas. Cancer Cell 23: 784-795, 2013.

69. Harris A: Resistance to anti-angiogenic therapy induced by hypoxia and notch signalling. EJC (Suppl) 8: 183-184, 2010.

70. Li JL, Sainson RCA, Oon CE, Turley H, Leek R, Sheldon H, Bridges E, et al: DLL4-Notch signaling mediates tumor resistance to anti-VEGF therapy in vivo. Cancer Res 71: 6073-6083, 2011.

71. Appelhoff RJ, Tian YM, Raval RR, Turley H, Harris AL, Pugh CW, Ratcliffe PJ, et al: Differential function of the prolyl hydroxylases PHD1, PHD2, and PHD3 in the regulation of hypoxia-inducible factor. J Biol Chem 279: 38458-38465, 2004.

72. Van Steenkiste C, Ribera J, Geerts A, Pauta M, Tugues S, Casteleyn C, Libbrecht L, et al: Inhibition of placental growth factor activity reduces the severity of fibrosis, inflammation, and portal hypertension in cirrhotic mice. Hepatology 53: 1629-1640, 2011.

73. Heindryckx F, Coulon S, Terrie E, Casteleyn C, Stassen JM, Geerts A, Libbrecht L, Allemeersch J, Carmeliet P, Colle I and Van Vlierberghe $\mathrm{H}$ : The placental growth factor as a target against hepatocellular carcinoma in an orthotopic mouse model. J Hepatol 58: 319-328, 2012.

74. Alison MR, Lin WR, Lim SML and Nicholson LJ: Cancer stem cells: in the line of fire. Cancer Treat Rev 38: 589-598, 2012.

75. Mathieu J, Zhang Z, Zhou WY, Wang AJ, Heddleston JM, Pinna CMA, Hubaud A, et al: HIF induces human embryonic stem cell markers in cancer cells. Cancer Res 71: 4640-4652, 2011.

76. Liang YJ, Zheng TS, Song RP, Wang JB, Yin DL, Wang LL, Liu HT, et al: Hypoxia-mediated sorafenib resistance can be overcome by EF24 through Von Hippel-Lindau tumor suppressor-dependent HIF-1 $\alpha$ inhibition in hepatocellular carcinomaa. Hepatology 57: 1847-1857, 2013.

77. Lehwald N, Tao GZ, Jang KY, Sorkin M, Knoefel WT and Sylvester KG: Wnt- $\beta$-catenin signaling protects against hepatic ischemia and reperfusion injury in mice. Gastroenterology 141: 707-718, 2011

78. Zhang Q, Bai XL, Chen W, Ma T, Hu QD, Liang C, Xie SZ, et al: Wnt/beta-catenin signaling enhances hypoxia-induced epithelial-mesenchymal transition in hepatocellular carcinoma via crosstalk with hif-1 alpha signaling. Carcinogenesis 34: 962-973, 2013.

79. Chen YX, Wong PP, Sjeklocha L, Steer CJ and Sahin MB: Mature hepatocytes exhibit unexpected plasticity by direct dedifferentiation into liver progenitor cells in culture. Hepatology 55: 563-574 2012.

80. Matsuoka J, Yashiro M, Doi Y, Fuyuhiro Y, Kato Y, Shinto O, Noda S, et al: Hypoxia stimulates the EMT of gastric cancer cells through autocrine TGFbeta signaling. PLoS One 8: e62310, 2013.

81. Copple BL: Hypoxia stimulates hepatocyte epithelial to mesenchymal transition by hypoxia-inducible factor and transforming growth factor-beta-dependent mechanisms. Liver Int 30 : 669-682, 2010

82. Matsuno Y, Coelho AL, Jarai G, Westvvick J and Hogaboam CM: Notch signaling mediates TGF-beta 1-induced epithelial-mesenchymal transition through the induction of Snail. Int J Biochem Cell Biol 44: 776-789, 2012.
83. Sahlgren C, Gustafsson MV, Jin S, Poellinger L and Lendahl U: Notch signaling mediates hypoxia-induced tumor cell migration and invasion. Proc Natl Acad Sci USA 105: 6392-6397, 2008

84. Lim SO, Kim HS, Quan X, Ahn SM, Kim H, Hsieh D, Seong JK, et al: Notch1 binds and induces degradation of Snail in hepatocellular carcinoma. BMC Biol 9: 83, 2011.

85. Goodman ZD, Ishak KG, Langloss JM, Sesterhenn IA and Rabin L: Combined hepatocellular-cholangiocarcinoma - a histologic and immunohistochemical study. Cancer 55: 124-135, 1985.

86. Lau CK, Yang ZF, Ho DW, Ng MN, Yeoh GCT, Poon RTP and Fan ST: An Akt/hypoxia-inducible factor-lalpha/platelet-derived growth factor-BB autocrine loop mediates hypoxia-induced chemoresistance in liver cancer cells and tumorigenic hepatic progenitor cells. Clin Cancer Res 15: 3462-3471, 2009.

87. Lee JI, Lee JW, Kim JM, Kim JK, Chung HJ and Kim YS: Prognosis of hepatocellular carcinoma expressing cytokeratin 19: comparison with other liver cancers. World J Gastroenterol 18: 4751-4757, 2012

88. Komuta M, Govaere O, Vandecaveye V, Akiba J, Van Steenbergen W, Verslype C, Laleman W, et al: Histological diversity in cholangiocellular carcinoma reflects the different cholangiocyte phenotypes. Hepatology 55: 1876-1888, 2012.

89. Tickoo SK, Zee SY, Obiekwe S, Xiao H, Koea J, Robiou C, Blumgart LH, et al: Combined hepatocellular-cholangiocarcinoma - a histopathologic, immunohistochemical, and in situ hybridization study. Am J Surg Pathol 26: 989-997, 2002.

90. Wang XQ, Ongkeko WM, Chen L, Yang ZF, Lu P, Chen KK, Lopez JP, et al: Octamer 4 (Oct4) mediates chemotherapeutic drug resistance in liver cancer cells through a potential Oct4AKT-ATP-binding cassette G2 pathway. Hepatology 52: 528-539, 2010.

91. Chu PGG, Ishizawa S, Wu E and Weiss LM: Hepatocyte antigen as a marker of hepatocellular carcinoma - an immunohistochemical comparison to carcinoembryonic antigen, CD10, and alpha-fetoprotein. Am J Surg Pathol 26: 978-988, 2002.

92. Omori N, Evarts RP, Omori M, Hu ZY, Marsden ER and Thorgeirsson SS: Expression of leukemia inhibitory factor and its receptor during liver regeneration in the adult rat. Lab Invest 75: 15-24, 1996.

93. Carpentier R, Suner RE, van Hul N, Kopp JL, Beaudry JB, Cordi $\mathrm{S}$, Antoniou A, et al: Embryonic ductal plate cells give rise to cholangiocytes, periportal hepatocytes, and adult liver progenitor cells. Gastroenterology 141: 1432-1438, 2011.

94. Ma S, Lee TK, Zheng BJ, Chan K and Guan XY: CD133(+) HCC cancer stem cells confer chemoresistance by preferential expression of the Akt/PKB survival pathway. Oncogene 27: 1749-1758, 2008.

95. Fan LN, He FR, Liu HX, Zhu J, Liu YX, Yin ZY, Wang L, et al: CD133: a potential indicator for differentiation and prognosis of human cholangiocarcinoma. BMC Cancer 11: 320, 2011.

96. Hou Y, Zou QF, Ge RL, Shen F and Wang YZ: The critical role of CD133(+)CD44(+/high) tumor cells in hematogenous metastasis of liver cancers. Cell Res 22: 259-272, 2012.

97. Knight B, Tirnitz-Parker JEE and Olynyk JK: C-kit inhibition by imatinib mesylate attenuates progenitor cell expansion and inhibits liver tumor formation in mice. Gastroenterology 135: 969-979, 2008 